\title{
Demographic Predictors of Listening to Radio and Watching TV Programmes among Agro-pastoralists in Tanzania
}

\author{
By Kelefa Mwantimwa*
}

\begin{abstract}
The study examined demographic predictors of the frequency of listening to the radio and watching TV programmes among agro-pastoralists of the Monduli and Bagamoyo districts in Tanzania. A data collection approach dominated by quantitative methods was used to collect data from 320 agro-pastoralists. The study's key findings suggest that ownership of radio and TV is a much stronger predictor of their utilisation while income, level of education, and age are less significant predictors. The study also reveals that male and married agro-pastoralists are more likely to frequently listen to and watch TV programmes than female and single agro-pastoralists. As a result, efforts to minimize the differences in the frequency of radio listening and TV viewing between male and female agro-pastoralists through providing education and eliminating contributing cultural practices and norms are important. Further, based on the findings of this study, more studies to measure demographic predictors in heterogeneous populations are encouraged.
\end{abstract}

Keywords: agro-pastoralists, demographic predictors, listening to radio, Tanzania, watching TV.

\section{Introduction}

Radio and TV are important mass media for enhancing access to information and entertainment in Tanzania. In 2013, $81 \%$ of Tanzanians had been listening to radio while $54 \%$ were likely to have watched TV programmes, thus suggesting that radio was by far the most popular mass media for accessing information and entertainment (Murthy, 2011; Twaweza, 2013). One of the motivating factors for radio usage is the cost and ease of access to radio stations, as radio was found to be cheaper compared to TV. The availability of infrastructure to support access to and use of radio and TV is another usage motivating factor. Currently, there are 47 radio stations and different TV stations in Tanzania providing a variety of products to users. Level of income and trust in particular media also play a pivotal role in determining the access to media devices other than radio. Accordingly, insufficient access to computers and internet increase the reliance on radio in rural areas. As a result, radios are available to the majority of agro-pastoralist communities, across all income levels and locations in Tanzania (Hampson et al., 2015; Murthy, 2011; URT, 2005).

Previously, TV appeared to be a luxury and thus the preserve of elite societies, thereby widening the gap between the rich and the poor. However, today even agro-pastoralist communities in one way or another have access to TV programmes. In fact, "at the highest income tier, radio, televisions, and mobile phone access has become identical" (Murthy, 2011). There are now numerous studies (e.g. Murthy, 2011; Twaweza, 2013) on the access to, usage, and impact of

*Lecturer, Information Studies Unit, University of Dar es Salaam, Tanzania. 
radio and TV among Tanzanians. However, how individual characteristics - such as ownership of radio and TV, age, level of education, and income - predict the frequency of listening to radio and watching TV programmes among agropastoralists in Tanzania is not known To fill this gap, this study aimed at examining how such individual characteristics predict the frequency of listening to radio and watching TV. The study was guided by six hypotheses:

H1: There is a strong relationship between ownership of radio and TV and the frequency of listening to radio and watching TV programmes.

H2: The ages of agro-pastoralists determine the frequency of listening to radio and watching TV programmes.

H3: Agro-pastoralists' level of education predicts the frequency of their listening to radio and watch TV programmes.

H4: Agro-pastoralists' income level predicts the frequency of their listening to radio and TV programmes.

H5: Male agro-pastoralists are more likely to listen to radio and watch TV programmes than females.

H6: Married agro-pastoralists are more likely to listen to radio and watch TV programmes than those who are single.

\section{Literature Review}

Literature suggests that as a result of a decrease in costs, radio ownership is no longer a problem among a majority of agro-pastoralists. For example, various studies (Kaur, Tall, Mwanga, \& Kisanga, 2015; Coulibaly et al., 2015; Churi, Mlozi, Tumbo, \& Casmir, 2012) found that radio is the most widespread medium used to access information. On a similar note, Murthy (2011) points out that radio, television and text messaging are the most highly trusted sources of information. In addition to that, the increased availability of radio stations in rural areas, such as through community radios, is found to be enhancing access to mass media. So, what are the predictors of the frequency of mass media usage? Churi et al. (2012) opine that the socio-economic status of an individual affects their ability to own and use media for accessing information. On the other hand, Jeffres and Atkin (1996) found that demographic characteristics play an insignificant role in predicting the usage of technology. Finn (1997) and Dupagne (1999) found some demographics to be stronger predictors of media awareness and adoption. However, noting from the study of Dupagne, income level is one of the insignificant variables in predicting media usage.

Divergently, Okwu and Iorkaa (2011) found that socio-economic status of rural farmers had a statistically significant relationship with the use of technology. Further, Murthy (2011) confirms that income plays a substantial role in determining household access to media devices such as TV, mobile phones, and radio. Churi et al. (2012) support the idea that an ability to buy media promotes the accessibility and usage of radio among farmers. The authors also attribute that to the fact that radio programmes have the ability to reach illiterate farmers. Surprisingly, Comstock and Scharrer (1999) claim that low household income is associated with 
more television viewing, while Anand and Krosnick (2005) noted that income had no impact on the usage of media. According to Anand and Krosnick (2005), "income by itself does not stratify the society in terms of access to or use of media" (p. 556). On a different note, they also found that age and level of education were good predictors of usage of different media.

The reviewed literature also discloses that there are disparities in terms of ownership and frequency of listening to and viewing TV programmes. In this regard, Hampson et al. (2015) observe that ownership of these tools was more common among male pastoralists than their female counterparts with the same applying to radio listening frequency. Similarly, Brown, Childers, Bauman, \& Koch (1990) found indications that the use of media varies depending on income, age, and gender. However, in contrast to other research, the authors found that females listened to radio and viewed TV programmes more frequently than males $(p<0.0001)$. This shows that a significant statistical difference was found in the frequency of listening to radio and viewing TV between males and females. In addition, the authors noted that married parents are more likely to own and frequently listen to radio than single parents. They explain that the possibility of single parents to possess a radio is minimal as compared to married parents. This suggests that family status is an important predictor of media usage.

On a different note, Anand and Krosnick (2005) found that individuals with lower and moderate levels of education watched TV programmes more than those with higher levels of education. Moreover, the authors also observe that the frequency of watching television steadily increases with age. Such observations refute Brown's et al. (1990) observation that revealed that television usage declined with age. In addition, Murthy (2011) found that individuals with higher income are more likely to frequently listen to radio and watch TV programmes than those with lower income. It is also pointed out that television viewing outside homes is an important factor for consideration, as only $27 \%$ have been found to have household access, while $41 \%$ watch TV weekly outside their homes. This applies more to rural viewers and people with low income who are more likely to communally watch TV outside their homes.

\section{Research Methodology}

\section{Study Design}

This is the architectural design of a study. A researcher makes decisions of what, where, when, and how data will be collected analysed, and measured. In all, "it constitutes the blueprint for the collection, measurement, and analysis of data" (Tavakoli, 2012, p. 546). In this study, a cross-sectional survey design was mainly used to gather data from agro-pastoralist communities of the Monduli and Bagamoyo districts. The design provides a quantitative or numeric description of trends and behaviour of a population by studying a sample of the large population. The design also allows for the collection of a large amount of data from a sizeable population in a highly economic way, and thus facilitates easy comparison (Cresswell, 2003; Singleton \& Straits, 2005; Mwantimwa, 2012). 


\section{Study Setting, Population, and Sampling}

The study was conducted in two (Monduli \& Bagamoyo) districts of Tanzania involving 320 agro-pastoralists from the districts. Monduli is located in the northeastern section of the country (Arusha region), while Bagamoyo is one of the six districts of the Pwani (Coast) Region. Most of the communities in the two districts are involved in crop farming and livestock keeping. Bagamayo and Monduli districts were purposefully selected as research settings because of the characteristics they possess, which facilitated the execution of this study. Different procedures were used to select respondents. The researcher used both probability and non-probability sampling to draw the sample. Specifically, the sampling process followed the following procedures:

- The two districts were purposively selected because a large portion of their populations are involved in crop farming and pastoralism;

- Villages involved in the study were then randomly selected from the two districts; and

- Agro-pastoralists who participated in the study were conveniently selected after failing to use a random sampling procedure. The readily available agro-pastoralists participated in the study.

Mainly, non-probability sampling was found to be more suitable due to the nature of the population the researcher was dealing with. In fact, the availability problem of the agro-pastoralists determined the sample selection process.

\section{Methods, Instruments, and Protocol}

In the process of data collection, a questionnaire with closed and open ended questions was used to collect data. The agro-pastoralists were asked to indicate their individual characteristics, such as gender, marital status, age, level of education, occupation, and income. The characteristics were used as predictors of the frequency of listening to radio and watching TV programmes. Accordingly, questions on ownership of radio and TV sets and the frequency of listening to radio and watching TV programmes were asked. The questions demanded different kinds of responses, including multiple choices, fill in, yes/no, and ranking. The researcher personally administered the questionnaire to the agro-pastoralists on a convenience basis.

\section{Validity of the Instruments}

Before the actual fieldwork, the researcher pre-tested the research instruments with 15 agro-pastoralists in the Bagamoyo district. The main purpose was to establish the credibility of the instruments. Questions with unclear words and meaning were changed to improve common understanding among the respondents. Besides that, the study made use of language translators to translate questions from English to local language, such as masai. This was an important technique to increase understanding of the questions and yield appropriate responses. 


\section{Reliability Test of the Instruments}

To gauge the consistency of the instruments used to collect data from the field, a Cronbach's Alpha test was used. Whereas the values closer to 1 suggest greater internal consistency, the values closer to 0 entail low consistency. It is important to note that an alpha value above 0.70 is recommended (Franco \& Garcia, 2017; Fornell \& Larcker, 1981). The values for the actual field data of the variables are summarized in Table 1.

Table 1. Reliability Test of the Instrument

\begin{tabular}{|l|c|c|}
\hline Variables & Number of items & Reliability \\
\hline Ownership of a radio and TV set & 3 & 0.751 \\
\hline Usage of the radio and TV & 3 & 0.811 \\
\hline Frequency of listening to radio programmes & 4 & 0.876 \\
\hline Frequency of watching TV programmes & 4 & 0.852 \\
\hline
\end{tabular}

On the whole, the Cronbach's Alpha values suggest that the instruments used to collect data from the field have internal consistency. This tells us that the instruments used to collect the data were appropriate. It is worth noting that the reliability scores for each item exceeded the 0.7 value representing substantial consistency (Franco \& Garcia, 2017).

\section{Analysis and Measurements}

Statistical Products for Service Solutions (SPSS) [IBM 20] was used to analyse the data collected from the field. Descriptive (i.e. frequency and percentage) and inferential (i.e. correlations and regressions) statistics were performed. Descriptive statistics were analysed to summarize demographic characteristics and establish trends and extents of radio and TV set ownership and usage, while inferential statistics were analysed to gauge the strengths and directions of the relationships between demographic predictors (i.e. ownership, age, level of education, marital status and gender) and the frequency of listening to the radio and watching TV programmes among the surveyed agropastoralists communities in Tanzania. The following equation was used to assess whether predictors have influence on the frequency of listening to radio and watching TV programmes: Frequency of listening to radio and watching TV = $b_{0}+b_{1}$ (Predictor) $+b_{2}$ (Predictor) ${ }^{2}$. This entails that there are different predictors for listening to radio and watching TV. In all, correlations and regressions were the models used to establish relationships, strengths, significant difference and direction of the relationships. 


\section{Results}

\section{Demographic Characteristics, Ownership, and Frequency of Listening to Radio and Watching TV}

This section presents results on the profile of respondents, ownership of radio and TV sets, and frequency of listening to radio and watching TV programmes. Apart from that, the section summarizes data outputs on the correlation between ownership and frequency of listening to radio and watching TV programmes among the selected agro-pastoralist communities of Bagamoyo and Monduli districts. Further, a regression analysis is performed to measure the influence of age, level of education, income, and ownership on the frequency of listening to radio and watching TV programmes. Table 2 summarises the demographic characteristics.

Table 2. Demographic Characteristics of the Respondents

\begin{tabular}{|c|c|c|c|}
\hline \multicolumn{2}{|c|}{ Demographic characteristics $(\mathrm{n}=\mathbf{3 2 0})$} & Frequency & Percent \\
\hline \multirow[t]{2}{*}{ Gender } & Female & 131 & 41 \\
\hline & Male & 189 & 59 \\
\hline \multirow{2}{*}{ Marital status } & Married & 268 & 83.8 \\
\hline & Not married & 51 & 16.1 \\
\hline \multirow[t]{5}{*}{ Age } & $19-28$ & 56 & 17.5 \\
\hline & $29-38$ & 80 & 25.0 \\
\hline & $39-48$ & 80 & 25.1 \\
\hline & $49-64$ & 42 & 13.0 \\
\hline & $>65$ & 62 & 19.4 \\
\hline \multirow[t]{4}{*}{ Level of education } & Never to school & 108 & 33.7 \\
\hline & Informal & 5 & 1.5 \\
\hline & Primary & 192 & 60.2 \\
\hline & Ordinary & 15 & 4.6 \\
\hline \multirow[t]{3}{*}{ Occupation } & Crop farming & 126 & 39.3 \\
\hline & Livestock keeping & 138 & 43.2 \\
\hline & Other business & 56 & 17.5 \\
\hline \multirow{3}{*}{$\begin{array}{l}\text { Income per month } \\
\text { (Tshs) }\end{array}$} & $0-45,000$ & 134 & 41.8 \\
\hline & $46,000-200,000$ & 161 & 50.2 \\
\hline & $>201,000$ & 26 & 8.0 \\
\hline
\end{tabular}

In terms of gender, the results show that more than half $(59 \%)$ of the respondents are male. The results also indicate that most $(83.8 \%)$ of the respondents are married, while only $16.1 \%$ of them are single. Regarding their level of education, a significant percentage $(60.2 \%)$ of the respondents stopped with primary school. A majority of respondents are involved in both crop farming and livestock keeping. The income of most of the respondents ranged from 46,000 to 200,000Tshs. The results on ownership and frequency of listening to radio and watching TV programmes are summarised in Table 3. 
Table 3. Ownership and Frequency of Listening to Radio and Watching TV

\begin{tabular}{|l|c|c|}
\hline Measured variables $(\mathbf{n}=\mathbf{3 2 0})$ & Frequency & Percent \\
\hline Ownership & 243 & 75.9 \\
\hline Radio & 21 & 6.5 \\
\hline TV & 203 & 63.5 \\
\hline Frequency of listening to radio programmes & 62 & 19.3 \\
\hline Frequently & 55 & 17.2 \\
\hline Occasionally & 63 & 19.5 \\
\hline Not listening & 216 & 67.6 \\
\hline Frequency of watching TV programmes & 41 & 12.8 \\
\hline Frequently
\end{tabular}

The results show that 243 (75.9\%) of the agro-pastoralists who participated in the study owned at least a radio, while $21(6.5 \%)$ of them owned a TV set. In all, a majority of the agro-pastoralists owned a radio, while only a few had TV sets. Regarding the frequency of listening to radio and watching TV, the results indicate that $203(63.5 \%)$ listened to radio and $63(19.5 \%)$ watched TV frequently, while $62(19.3 \%)$ of them listened to radio and $216(67.6 \%)$ watched TV programmes occasionally. Further, $55(17.2 \%)$ of the respondents said they do not listen to radio at all, while $41(12.8 \%)$ said they do not watch TV programmes at all. In sum, these results show that most of the agro-pastoralists frequently listen to radio, but only occasionally watch TV programmes.

\section{Bivariate Correlations Analysis}

A Pearson bivariate correlations analysis was performed to measure the relationship, strength, and significance level as summarised in Table 4.

Table 4. Correlations on Ownership and Frequency of Listening to Radio and Watching TV

\begin{tabular}{|l|l|c|c|c|}
\hline \multirow{4}{*}{ Radio } & Correlations (n=320) & Ownership & Frequency of listening \\
\cline { 2 - 5 } & \multirow{4}{*}{ Ownership } & Rho & 1 & $0.678^{* *}$ \\
\cline { 3 - 5 } & & Sig. & & 0.004 \\
\cline { 2 - 5 } & \multirow{2}{*}{ Listening } & Rho & $0.678^{* *}$ & 1 \\
\cline { 3 - 5 } & & Sig. & 0.004 & \\
\hline \multirow{7}{*}{ CV } & Correlations (n=320) & Ownership & Frequency of watching \\
\cline { 2 - 5 } & \multirow{2}{*}{ Ownership } & Rho & 1 & $0.545^{* *}$ \\
\cline { 3 - 5 } & & Sig. & & 0.006 \\
\cline { 2 - 5 } & \multirow{2}{*}{ Watching } & Rho & $0.545^{* *}$ & 1 \\
\cline { 3 - 5 } & & Sig. & 0.006 & \\
\hline
\end{tabular}

H1: There is a strong relationship between ownership of radio and TV, and the frequency of listening to radio and watching TV programmes. Between radio ownership and the frequency of listening to the radio, the Pearson correlations results (Rho=0.678; $p=0.008)$ reveal a strong and significant relationship. The results also indicate that a moderate relationship $(\mathrm{Rho}=0.545 ; p=0.006)$ exists 
between ownership and frequency of watching TV programmes. These results therefore support the hypothesis on the relationship between ownership of radio and $\mathrm{TV}$, and frequency of listening to radio and watching TV programmes.

\section{Multiple Regression Analysis}

A multiple and logistic regression analysis was performed to measure the influence of TV set and radio ownership, income, age, level of education, gender, and marital status on the frequency of listening to radio and watching TV programmes. While Table 5 provides outputs for ANOVA, Table 6 presents coefficients that provide estimates of the beta and significance values of ownership, income, age, and level of education.

Table 5. ANOVA

\begin{tabular}{|c|c|c|c|c|c|c|}
\hline \multicolumn{7}{|c|}{ Listening to radio } \\
\hline \multicolumn{2}{|c|}{ Model } & Sum of Squares & Df & Mean Square & $\mathbf{F}$ & Sig. \\
\hline \multirow[t]{3}{*}{1} & Regression & 18.822 & 5 & 3.764 & 4.943 & $0.000^{\mathrm{b}}$ \\
\hline & Residual & 236.324 & 310 & 0.761 & & \\
\hline & Total & 255.146 & 315 & & & \\
\hline \multicolumn{7}{|c|}{ Watching TV } \\
\hline \multirow[t]{3}{*}{1} & Regression & 12.724 & 5 & 2.545 & 6.659 & $0.000^{b}$ \\
\hline & Residual & 119.622 & 313 & 0.382 & & \\
\hline & Total & 132.346 & 318 & & & \\
\hline
\end{tabular}

a: Dependent Variable: Frequency of listening to radio and watching TV programmes.

b: Predictors: Ownership of radio set, Age, Income, Level of education.

Table 6. Coefficients

\begin{tabular}{|l|l|c|c|c|c|c|}
\hline Model & \multicolumn{2}{|c|}{$\begin{array}{c}\text { Unstandardized } \\
\text { Coefficients }\end{array}$} & $\begin{array}{c}\text { Standardized } \\
\text { Coefficients }\end{array}$ & \multirow{2}{*}{ T } & \multirow{2}{*}{ Sig. } \\
\cline { 3 - 7 } \multicolumn{2}{|c|}{$\begin{array}{l}\text { Listening } \\
\text { to radio }\end{array}$} & B & Std. Error & Beta & & \\
\cline { 2 - 7 } & Age & 2.622 & 0.354 & & 7.399 & 0.000 \\
\cline { 2 - 7 } & Level of education & 0.030 & 0.036 & 0.005 & 0.090 & 0.928 \\
\cline { 2 - 7 } & Income & 0.147 & 0.055 & -0.113 & -1.869 & 0.063 \\
\hline \multirow{3}{*}{$\begin{array}{l}\text { Watching } \\
\text { TV }\end{array}$} & (Constant) & 1.828 & 0.081 & -0.102 & -1.805 & 0.072 \\
\cline { 2 - 7 } & Age & 0.011 & 0.010 & 0.060 & 1.047 & 0.296 \\
\cline { 2 - 7 } & Level of education & 0.015 & 0.014 & 0.062 & 1.104 & 0.270 \\
\cline { 2 - 7 } & Income & 0.019 & 0.022 & 0.048 & 0.861 & 0.390 \\
\hline
\end{tabular}

a: Dependent variable: Frequency of listening to radio.

b: Dependent variable: Frequency of watching TV.

The ANOVA outputs indicate that the results are significantly good to predict the frequency of listening to radio and watching TV programmes. However, the outputs do not tell us about the contribution of individual variables in the multiple regression analysis. In general, the values of the regression coefficients $b$ represent a change in the outcome resulting from a unit change in the predictors. Taking these into account, some of the hypotheses are supported by the findings, while others are not (Table 6). 
H2: The ages of agro-pastoralists partially predict the frequency of listening to radio and watching TV programmes. Regarding the frequency of listening to radio programmes, the value for age $(b=0.030)$ indicates that as age increases by one unit, frequency of listening to radio insignificantly increases by 0.030 units. Apart from that, the outputs for the frequency of watching TV programmes show that as the value for age increases by one unit, the frequency of watching TV programmes increases by 0.011 units. Accordingly, age has been found to be an unimportant predictor of the frequency of listening to radio and watching TV programmes due to the small effect recorded. This hypothesis is therefore rejected.

H3: The level of education of the agro-pastoralist predicts the frequency of listening to radio and watching TV programmes. On frequency of listening to radio, the outputs for education $(b=0.102)$ suggests that with an increase of level of education by one unit, the frequency of listening to radio insignificantly $(p=0.063)$ increases by 0.102 unit of coefficient. Accordingly, the value for education $(b=0.015)$ with an increase in the level of education, the frequency of watching TV programmes increases by 0.015 unit of coefficient insignificantly $(p=0.270)$. On the whole, an increase of level of education is insignificant since the $p$ value is $>0.05$. This suggests that levels of education of the surveyed agropastoralists are not important predictors of the frequency of listening to the radio and watching TV programmes.

H4: Agro-pastoralists' income levels predict the frequency of listening to radio and watching of TV programmes. The result discloses that with an increase of one unit of income $(b=0.147)$, the frequency of listening to radio insignificantly ( $p=0.07$ ) increases by 0.147 unit. Regarding frequency of watching TV, the value for income $(b=0.019)$ discloses that with an increase of one unit of income, the frequency of watching TV programmes increases by 0.019 unit insignificantly $(p=0.390)$. In all, an increase in income is insignificant since the $p$ value is $>0.05$. These suggest that levels of income of the surveyed agro-pastoralists are not important predictors of the frequency of listening to the radio and watching TV programmes.

Further, logistic regression was performed to measure the influence of gender and marital status on listening to radio and watching TV programmes. Table 7 presents the logistic regression on gender and marital status (Table 7).

Table 7. Logistic Regression on Gender and Marital Status

\begin{tabular}{|l|c|c|c|c|c|}
\hline Frequency & Odds Ratio & Std. Err. & $\mathbf{z}$ & $\mathbf{P}>\mathbf{z}$ & [95\% Conf. Interval] \\
\hline Listening to radio \\
\hline $\begin{array}{l}\text { Sex (Male }=1) \\
\text { Marital status } \\
\text { (Married = 1) }\end{array}$ & 0.819 & 0.240 & -1.68 & 0.485 & {$[0.461-1.455]$} \\
\hline _cons & 4.352 & 1.481 & 4.32 & 0.000 & {$[2.234-8.480]$} \\
\hline Watching TV & 0.284 & 0.246 & -1.79 & 0.147 & {$[0.052-1.556]$} \\
\hline Sex (Male =1) & 1.262 & 0.329 & 0.89 & 0.372 & {$[0.757-2.103]$} \\
\hline $\begin{array}{l}\text { Marital status } \\
\text { (Married =1) }\end{array}$ & 1.606 & 0.576 & 1.32 & 0.188 & {$[0.794-3.247]$} \\
\hline _cons & 0.143 & 0.124 & -2.23 & 0.026 & {$[0.026-0.791]$} \\
\hline
\end{tabular}


H5: Men are more likely to listen to radio and watch TV programmes than women. The results show that the probability odds ratio on the frequency of listening to radio programmes for men is 0.82 times higher than that for women respondents. On the frequency of watching TV, the data outputs indicate that the odds ratio for men is 1.26 times higher than that for female. These findings inform that men are likely to listen to radio and watch TV programmes than women. In other words, the results support the hypothesis.

H6: Married agro-pastoralists are more likely to listen to radio and watch TV programmes than those single. The results signify that the probability odds ratio on the frequency of listening to radio programmes for married respondents it is 4.35 times higher than that for those single. On the frequency of watching $\mathrm{TV}$, the data outputs suggest that the odds ratio for married respondents had an odds ratio 1.61 times higher than the one for those single. These entail that married agro-pastoralists are more likely to listen to radio and watch TV programmes than that for those single. In all, the findings confirm the hypothesis.

\section{Discussion}

The empirical findings for the overall sample suggest that radio and TV set ownership are strong predictors of the frequency of listening to radio and watching TV programmes. This is confirmed by the findings that showed a significant relationship between ownership and frequency of listening to radio and watching to TV programmes. The results show that Monduli and Bagamoyo agropastoralists who owned a radio and TV set are more likely to listen to the radio and watch TV programmes more frequently than those who do not. In contrast, Murthy (2011) attributes the popularity of radio to its ability to reach illiterate farmers, when in fact, a significant number of agro-pastoralists owned radios because they are cheaper than TV sets. The researcher also observed that some agro-pastoralists are using mobile phones to tune in to radio stations. In this respect, mobile phones add a new model of ownership and access to radio programmes, thus increasing the popularity of this mechanism of information access among pastoralist communities. What does this entail? This means that the incorporation of radio technology in mobile phones allows agro-pastoralists to own two technologies in one device, which adds to the value of mobile phones.

Additionally, it is important to note that higher income is not always the only determinant of radio and TV ownership or of listening to and viewing programmes. Other surrounding factors, such as power, culture, customs, and accessibility of radio and TV frequencies, should be taken together into considerations. In fact, in the surveyed villages, access to the national power supply grid is a significant problem; the TV set owners often rely on generators and solar power. Surprisingly, the findings disclose that a majority of the agropastoralists occasionally watched TV programmes despite not owning TV set. This affirms that the model of watching TV programmes does not depend on ownership. In the surveyed villages, a majority of agro-pastoralists accessed TV in places like TV show rooms, clubs, and at their neighbours' houses. Indeed, 
although ownership is a strong predictor of frequency usage, lack of possession of a TV set is not a significant barrier to occasionally watching TV programmes. Murthy (2011) concurs with these findings by stating that television viewership outside homes is an important factor for consideration. This type of access to TV programmes is common in rural areas where people with lower tier income are more likely to communally watch TV outside their homes.

Apart from that, the results indicate that age, levels of income and education are insignificant predictors of the frequency of listening to radio and watching TV programmes. In other words, changes in agro-pastoralists' age, level of education, or income have a small influence on their frequency of listening to radio and watching TV programmes. The differences in terms of income and level of education among the agro-pastoralists in the surveyed villages are found to be insignificant. A noticeable percentage of the agro-pastoralists who participated in the study left primary school or had only gone through informal education. The results also reveal that a small percentage of the agro-pastoralists had gone beyond primary level of education. This insignificant difference in education might be the reason for the minimal effect of education on the frequency of radio listening and TV watching registered during the study.

However, in terms of income, a study by Murthy (2011) found that individuals with higher income are more likely to frequently listen to radio and watch TV programmes than those with lower income. On the other hand, Dupagne (1999) found that income had no impact on the usage of television. Surprisingly, Comstock and Scharrer (2000) found that low income level is associated with more television viewing. The findings from the present study do not support those from any of the above mentioned studies because income was not found to be a good predictor of the frequency of listening to radio and watching TV programmes. However, it has to be pointed out that the number of respondents with higher income in this study is insignificant, hence the difficulty in proving the strength of income level in determining access to and usage of media, such as radio and TV. Other studies (e.g. Churi et al., 2012; Okwu \& Iorkaa, 2011) concluded that socio-economic status of rural farmers has a statistically significant relationship with and effect on the ability to posses and use media. However, their findings have not specified the socio-economic factors that affect ownership, listening to radio, and watching TV programmes. All in all, there is a divergence between the existing knowledge and the current findings.

Furthermore, the findings have also revealed that level of education among agro-pastoralists is a less important predictor of the frequency of listening to radio and watching TV. As a result, these findings cannot confirm or deny the facts that exist in the numerous literatures available. For example, this study does not confirm or invalidate Anand and Krosnick's (2005) findings, which revealed that individuals with lower and moderate levels of education more frequently watch TV than those with a higher level of education. Furthermore, the findings affirm that men are more likely to frequently listen to radio and watch TV programmes than women. This is due to the fact that women in the surveyed agro-pastoralist villages spend a lot of time on the farms, fetching water and firewood, and attending to their families. Moreover, most men tend to keep their radios around 
and have control over their usage, thus providing more opportunities to listen to them. Adding to that, men in the surveyed villages have more time to visit clubs and TV show rooms, while women are less likely to find time to be in such places. Hampson et al. (2015) concur with these findings by stating that men listen to radio more frequently than women. Regarding marital status, married agropastoralists are found to be more likely to frequently listen to radio and watch TV programmes. However, the fact that the majority of agro-pastoralists who participated in the study are married might have contributed to this finding.

\section{Conclusion}

The influence of demographic characteristics on homogeneous populations frequency of watching TV and listening to radio has been found to be insignificant with the exception of ownership of the radio and TV. Demographic characteristics, such as income, level of education, and age, are not significant potential predictors of the frequency of listening to radio and watching TV programmes among the surveyed agro-pastoralists. A disparity in frequency of listening to radio and watching TV programmes between men and women was observed, as men have been found to be more likely to listen to radio and watch TV programmes frequently. Mobile phones are changing the modality of ownership, access to, and use of radio with their two in one technology (radio incorporated in mobile phones). In that manner, mobile phones are enhancing the accessibility of radio services. Based on these findings, deliberate efforts to abolish cultural practices, norms, and beliefs among the surveyed agro-pastoralists should be taken by the government, societies, and other development partners in order to enhance access to and usage of media. Evidently, education is an important tool for minimising existing gaps in the accessibility and usability of information resources among communities, thus helping to ensure people's right to information. This should be seen as a fundamental and constitutional right for all, regardless of race, geographical location, status, education level, or religion.

\section{References}

Anand. S., \& Krosnick, J. A. (2005). Demographic predictors of media use among infants, toddlers and preschoolers. American Behavioral Scientist, 48(5), 539-561.

Brown, J. D., Childers K. W., Bauman, K. E., Koch, G. G. (1990). The influence of new media and family structure on young adolescents' television and radio use. Communication Research, 17(1), 65-82.

Compstock, G. A., \& Scharrer, E. (1999). Television: what's on, who's watching, and what it means. San Diego, CA: Academic Press.

Coulibaly, Y. J., Mango, J., Swamila, M., Tall, A., Kaur, H., \& Hansen, J. (2015). What climate services do farmers and pastoralists need in Tanzania? Baseline study for the GFCS Adaptation Program in Africa. CCAFS Working Paper no. 
110. CGIAR Research Program on Climate Change, Agriculture and Food Security (CCAFS). Copenhagen, Denmark.

Churi, A. J., Mlozi, M. R. S., Tumbo, S. D., Casmir, R. (2012). Understanding farmers information communication strategies for managing climate risks in rural semiarid areas, Tanzania. International Journal of Information and Communication Technology Research, 2(11), 838-845.

Creswell, J. W. (2003). Research design: qualitative, quantitative and mixed methods, approaches (2nd ed.). California: Thousand Oaks-SAGE Publications.

Dupagne, M. (1999). Exploring the characteristics of potential higher-definition television adopter. The Journal of Media Economics, 12(1), 35-50.

Finn, S. (1997). Origins of media exposure-linking personality traits to TV, radio, print and film use. Communication Research, 24(5).

Fornell, C., \& Larcker, D. (1981). Evaluating structural equation models with unobservable variables and measurement error. Journal of Marketing Research, $18(1), 39-50$.

Franco, M., \& Garcia, M. (2017). Drivers of ICT acceptance and implementation in micro-firms in the estate agent sector: influence on organizational performance. Information Technology for Development. DOI: 10.1080/02681102.2017.137 9378.

Hampson, K. J., Chapota, R., Emmanuel, J., Tall, A., Huggins-Rao, S., Leclair, M., Perkins, K., Kaur, H., and Hansen, J. (2015). Delivering climate services for farmers and pastoralists through interactive radio: scoping report for the GFCS adaptation programme in Africa. CCAFS Working Paper no. 111. CGIAR Research Program on Climate Change, Agriculture and Food Security (CCAFS). Copenhagen, Denmark.

Jeffres, L., \& Atkin, D. (1996). Predicting use of technologies for communication and consumer needs. Journal of Broadcasting \& Electronic Media, 40(3), 18-330.

Kaur, H., Tall, A., Mwanga, S., \& Kisanga, J. (2015). Scaling up climate information services for farmers and pastoralists in Tanzania through ICTS and rural radio. CGIAR Research Program on Climate Change, Agriculture and Food Security (CCAFS). Copenhagen, Denmark.

Murthy, G. (2011). Tanzania media environment: current access, potential for growth and strategies for information dissemination. London: InterMedia Survey Institute.

Mwantimwa, K. (2012). The use of pull information mode to support poverty reduction programmes in rural Tanzania: a case of Monduli and Bagamoyo districts (Unpublished PhD Thesis). University of Antwerpen, Belgium.

Okwu, O. J., \& Iorkaa, T. I. (2011). An assessment of farmers' use of new information and communication technologies as sources of agricultural information in Ushongo local government area, Benue State, Nigeria. Journal of Sustainable Development in Africa, 13(2).

Singleton, R. A., \& Straits, B. (2005). Approaches to social science research. Oxford: Oxford University Press.

Tavokali, H. (2012). A dictionary of research methodology and statistics in applied linguistics. Teharan: Rahnama Press.

Twaweza. (2013). Information demand and supply in Tanzania: voice of the people. Brief No.4.

URT - United Republic of Tanzania. (2005). Community television for the poor: a scoping study. Reading: DFID. 
